\title{
Incorporation of Si atoms into CrCoNiFe high-entropy alloy: a DFT study
}

S. Assa Aravindh ${ }^{1}$, Andrey A. Kistanov ${ }^{1, *}$, Matti Alatalo ${ }^{1}$, Jukka Kömi², Marko Huttula ${ }^{1}$, Wei Cao ${ }^{1}$

${ }^{1}$ Nano and Molecular Systems Research Unit, University of Oulu, 90014 Oulu, Finland

${ }^{2}$ Materials and Mechanical Engineering Unit, University of Oulu, 90014 Oulu, Finland

*Email: andrey.kistanov@oulu.fi

\section{Abstract}

Density functional theory based computational study has been conducted in order to investigate the effect of substitution of $\mathrm{Cr}$ and $\mathrm{Co}$ components by $\mathrm{Si}$ on the structure, mechanical, electronic, and magnetic properties of the high entropy alloy $\mathrm{CrCoNiFe}$. It is found that the presence of a moderate concentration of Si substitutes (up to $12.5 \%$ ) does not significantly reduce the structural and mechanical stability of $\mathrm{CrCoNiFe}$ while it may modify its electronic and magnetic properties. Based on that, $\mathrm{Si}$ is proposed as a cheap and functional material for partial substitution of $\mathrm{Cr}$ or $\mathrm{Co}$ in $\mathrm{CrCoNiFe}$.

Keywords: high-entropy alloys, density-functional theory, $\mathrm{CrCoNiFe}, \mathrm{Si}$, substitution

\section{Introduction}

High-entropy alloys (HEAs) have been an active area of research in the metallic materials regime since they were first proposed by Yeh et al. [1]. The broad range of HEAs consists of alloys composed of five or more elements, within the concentration range of 5-35 at.\% and they are mostly characterized by unique features such as high entropy, slow diffusion and lattice distortions [2]. Instead of the conventional alloys based on an individual solvent element, HEAs opens up a whole new world owing to the compositional complexity and possible element combinations.

Previous research on HEAs were mainly focused on various combinations of metal elements such as $\mathrm{Al}, \mathrm{Co}, \mathrm{Cr}, \mathrm{Cu}, \mathrm{Fe}$ and $\mathrm{Ni}$ [3-8]. However, it is also possible to form 'derived' alloys including other elements such as $\mathrm{Nb}, \mathrm{Sn}$ etc. [9-11]. The entropy modification of the conventional alloys was also done by either replacing the solvent or the solute [12]. One such alloy is Fe-Mn-Al-Si-C system, where entropy enhancement of the solute has been conducted [13]. Another alloy similar to this system is $\mathrm{CrCoNiFe}$, which has shown the potential to be tuned by addition of other alloying elements [14]. One aspect which makes $\mathrm{CrCoNiFe}$ less attractive is the expensive $\mathrm{Co}$, and hence alloys containing reduced Co compositions has an advantage. Hence the challenge is to retain the alloy properties, when reducing the Co concentration. Many elements have been explored in altering the Co content $[15,16]$. $\mathrm{CoCrFeMnNi}$ alloys were proved to be beneficial for additive manufacturing [17], while diluted $\mathrm{Al}$ and $\mathrm{Mb}$ are predicted to influence twinning which in turn increased the mechanical properties [14]. It has been shown that the betterment of mechanical properties is possible by introducing atoms which alters the ionic to atomic radius ratio and valence electron count. The addition of Al has been shown to influence the phase changes in $\mathrm{CrCoNiFe}$ alloys [18], while $\mathrm{Cu}$ introduces high entropy effects, to benefit its application in ceramics [19]. Earlier Raabe et al [13] have investigated Fe-Mn-Al-Si-C high 
entropy steels, and could successfully stabilize a single homogeneous FCC phase with high tensile strength and elongations. Interestingly this high entropy steel possessed enhanced mechanical properties compared to conventional steels. Si has also been investigated in the context of light weight high entropy alloys such as $\mathrm{Al}_{20} \mathrm{Be}_{20} \mathrm{Fe}_{10} \mathrm{Si}_{15} \mathrm{Ti}_{35}$ [20]. Further $\mathrm{Si}$ addition has been shown to increase the yield strength and ductility of the high entropy alloy $\mathrm{CoFeNiSi}_{x}[21]$, where the change in Si concentration has shown to influence the phase structure as well. The addition of Si also significantly affected the saturation magnetization of these alloys. Though there have been some studies focusing on the positive aspects of adding $\mathrm{Si}$ to the quaternary alloy systems focusing on various aspects, a comprehensive analysis including structural, magnetic, electronic and mechanical properties is needed to understand further material modelling of high entropy alloys. In the present study we introduce $\mathrm{Si}$ to the $\mathrm{CrCoNiFe}$ system and study the structural, magnetic, electronic and elastic properties. Our primary aim is to replace the magnetic atoms and investigate the effect of Si towards the overall change in properties of the alloy system.

\section{Methods}

Computational simulations were performed in the framework of the spin-polarized density functional theory (DFT) based on plane-wave method and the generalized gradient approximation (GGA) parameterized by Perdew-Burke-Ernzerhof (PBE) exchange-correlation functional [22] as implemented in the Vienna Ab initio Simulation Package (VASP) [23]. The structures were fully relaxed until the atomic forces and total energy were smaller than $0.01 \mathrm{eV} / \AA$ and $10^{-8} \mathrm{eV}$, respectively. An energy cutoff of $520 \mathrm{eV}$ was adopted for the expansion of electronic wavefunctions. Periodic boundary conditions were applied in all three directions. The first Brillouin zone was sampled with k-point mesh grids of $5 \times 5 \times 5$ (for the structure optimization) and $10 \times 10 \times 10$ (for the electronic structure calculations) using the Monkhorst-Pack scheme. The elastic constants were derived from the strainstress relationship as implemented in the VASP code. An analysis of elastic tensors was partly conducted in an open-source application ELATE [24].

\section{Results and Discussion}

Structure. Figure 1 represents the supercell of $\mathrm{CrCoNiFe}$ and a schematic representation of $\mathrm{Si}$ substitution. Si-containing structures were created by replacing $\mathrm{Cr}$ or $\mathrm{Co}$ atoms with $\mathrm{Si}$ in the $\mathrm{CrCoNiFe}$ matrix. 


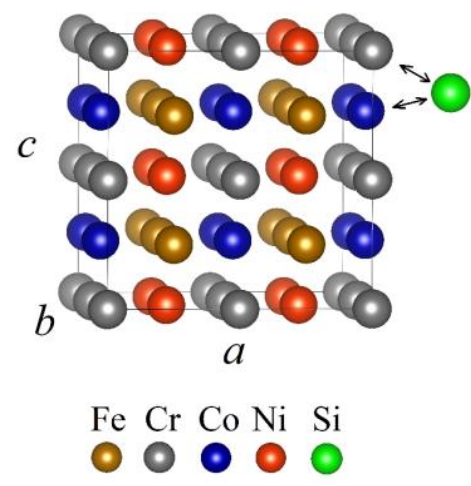

Figure 1. The supercell of $\mathrm{CrCoNiFe}$ and a schematic representation of Si substitution.

Table 1 gives the calculated equilibrium lattice constants of $\mathrm{CrCoNiFe}, \mathrm{Si}_{\mathrm{x}} \mathrm{Cr}_{1-\mathrm{x}} \mathrm{CoNiFe}$, and $\mathrm{Si}_{\mathrm{y}} \mathrm{CrCo}_{1-\mathrm{y}} \mathrm{NiFe}$ crystals. The calculated lattice parameters $a, b$, and $c$ of $\mathrm{CrCoNiFe}$ to be $3.492 \AA$ for the unit cell and $6.984 \AA$ for the $2 \times 2 \times 2$ supercell. The obtained results are well aligned with theoretical predictions [25] and experimental observations [26, 27]. These data are also given in Table 1 for comparison.

Table 1. The calculated lattice parameters $a, b, c$, and formation energy $E_{\mathrm{f}}$ of $\mathrm{Si}_{\mathrm{x}} \mathrm{Cr}_{1-\mathrm{x}} \mathrm{CoNiFe}_{\mathrm{F}}$ and $\mathrm{Si}_{\mathrm{y}} \mathrm{CrCo}_{1-}$ yNiFe crystals.

\begin{tabular}{|c|c|c|c|c|}
\hline & $a, \AA$ & $b, \AA$ & $c, \AA$ & $E_{\mathrm{f}, \mathrm{eV} / \text { atom }}$ \\
\hline CrCoNiFe (unitcell) & 3.492 & 3.492 & 3.492 & 0.08 \\
\hline $\begin{array}{c}\mathrm{CrCoNiFe}\left(2^{\times} 2^{\times 2}\right. \\
\text { supercell })\end{array}$ & 6.984 & 6.984 & 6.984 & 0.08 \\
\hline CrCoNiFe (unitcell) & 3.571 & 3.571 & 3.571 & 0.08 \\
\hline \multicolumn{5}{|l|}{ Ref. results $[26,27]$} \\
\hline \multicolumn{5}{|l|}{$\mathrm{Si}_{\mathrm{x}} \mathrm{Cr}_{1-\mathrm{x}} \mathrm{CoNiFe}$} \\
\hline$x=12.5$ & 7.168 & 6.992 & 6.810 & 0.01 \\
\hline$x=25$ & 7.097 & 7.020 & 6.957 & 0.12 \\
\hline$x=37.5$ & 7.093 & 7.025 & 6.945 & 0.26 \\
\hline$x=50$ & 6.999 & 7.075 & 7.145 & 0.34 \\
\hline \multicolumn{5}{|l|}{$\mathrm{Si}_{y} \mathrm{CrCo}_{1-\mathrm{y}} \mathrm{NiFe}$} \\
\hline$y=12.5$ & 7.224 & 6.991 & 6.924 & -0.09 \\
\hline$y=25$ & 7.310 & 6.891 & 6.902 & -0.06 \\
\hline$y=37.5$ & 7.339 & 6.888 & 6.879 & -0.03 \\
\hline
\end{tabular}

The formation energy $E_{\mathrm{f}}$ of $\mathrm{CrCoNiFe}$ and its Si-containing derivatives is defined as

$$
E_{\mathrm{f}}=\left(E_{\mathrm{tot}}-N_{\mathrm{Cr}} E_{\mathrm{Cr}}-N_{\mathrm{Co}} E_{\mathrm{Co}}-N_{\mathrm{Ni}} E_{\mathrm{Ni}}-N_{\mathrm{Fe}} E_{\mathrm{Fe}}-N_{\mathrm{Si}} E_{\mathrm{Si}}\right) /\left(N_{\mathrm{Cr}}+N_{\mathrm{Co}}+N_{\mathrm{Ni}}+N_{\mathrm{Fe}}+N_{\mathrm{Si}}\right)
$$


where $E_{\mathrm{tot}}$ is the total energy of the unitcell, $E_{\mathrm{Cr}}, E_{\mathrm{Co}}, E_{\mathrm{Ni}}, E_{\mathrm{Fe}}$, and $E_{\mathrm{Si}}$ correspond to the total energy per atom (the energy of a single atom in the bulk structure) of $\mathrm{Cr}, \mathrm{Co}, \mathrm{Ni}, \mathrm{Fe}$, and $\mathrm{Si}$ elements, respectively. The calculated $E_{\mathrm{f}}$ are also collected in Table 1.

For $\mathrm{CrCoNiFe}$ the calculated $E_{\mathrm{f}}$ of $0.08 \mathrm{eV} /$ atom is similar to that reported in reference [28]. At the Si concentration of $12.5 \%$ upon the substitution of $\mathrm{Cr}$ by $\mathrm{Si} E_{\mathrm{f}}$ decreases almost to zero, while the increase of $\mathrm{Si}$ concentration to $25 \%$ and above increases the formation energy of the $\mathrm{Si}_{\mathrm{x}} \mathrm{Cr}_{1-\mathrm{x}} \mathrm{CoNiFe}$ crystal. The substitution of $\mathrm{Co}$ by $\mathrm{Si}$ lowered $E_{\mathrm{f}}$ of the $\mathrm{Si}_{\mathrm{y}} \mathrm{CrCo}_{1-\mathrm{y}} \mathrm{NiFe}$ crystal. Particularly, at $12.5 \%$, $25 \%$, and $37.5 \%$ of $\mathrm{Si} E_{\mathrm{f}}$ decreases to $-0.09,-0.06$, and $-0.03 \mathrm{eV} /$ atom, respectively. Therefore, in terms the substitution of $\mathrm{Co}$ by $\mathrm{Si}$ is more energetically favourable compared to the substitution of $\mathrm{Cr}$ by $\mathrm{Si}$. Importantly, in both considered cases, the presence of $\mathrm{Si}$ of a concentration of $12.5 \%$ increases the stability of the crystal. It should be noted that the formation energy of $\mathrm{Si}_{\mathrm{x}} \mathrm{Cr}_{1-\mathrm{x}} \mathrm{CoNiFe}$ alloys with the $\mathrm{Si}$ concentration higher than $12.5 \%$ is beyond $0 \mathrm{eV}$. Therefore, the introduction of $\mathrm{Si}$ in these cases may cause the precipitation of intermetallic phases as it has predicted for the $\mathrm{Fe}-\mathrm{Co}-\mathrm{Ni}-\mathrm{Si}$ alloys [21].

Elastic properties and stability. The calculated elastic constants $C_{i j}$ of $\mathrm{Si}_{\mathrm{x}} \mathrm{Cr}_{1-\mathrm{x}} \mathrm{CoNiFe}$ and $\mathrm{Si}_{\mathrm{y}} \mathrm{CrCo}_{1-}$ yNiFe crystals are collected in Table 2.

Table 2. The elastic constants of the orthorhombic $\mathrm{Si}_{\mathrm{x}} \mathrm{Cr}_{1-\mathrm{x}} \mathrm{CoNiFe}$ and $\mathrm{Si}_{\mathrm{y}} \mathrm{CrCo}_{1-\mathrm{y}} \mathrm{NiFe}$ crystals, where $\mathrm{x}$ and $\mathrm{y}$ are the concentration of the element.

\begin{tabular}{c|c|c|c|c|c|c|c|c|c}
\hline & $\mathrm{x}=0$ & $\mathrm{x}=12.5$ & $\mathrm{x}=25$ & $\mathrm{x}=37.5$ & $\mathrm{x}=50$ & $\mathrm{y}=12.5$ & $\mathrm{y}=25$ & $\mathrm{y}=37.5$ & $\mathrm{y}=50$ \\
\hline $\mathrm{C}_{11}, \mathrm{GPa}$ & 386.94 & 385.27 & 339.68 & 341.93 & 315.71 & 293.48 & 340.36 & 309.57 & 285.25 \\
\hline $\mathrm{C}_{12}, \mathrm{GPa}$ & 196.62 & 177.56 & 179.20 & 166.71 & 168.90 & 121.49 & 156.52 & 249.76 & 244.89 \\
\hline $\mathrm{C}_{13}, \mathrm{GPa}$ & 196.39 & 194.78 & 175.24 & 176.92 & 148.94 & 110.44 & 148.31 & 140.81 & 153.35 \\
\hline $\mathrm{C}_{21}, \mathrm{GPa}$ & 196.63 & 177.56 & 179.20 & 166.71 & 168.90 & 121.49 & 156.52 & 249.76 & 244.89 \\
\hline $\mathrm{C}_{22}, \mathrm{GPa}$ & 370.41 & 365.29 & 303.67 & 316.62 & 272.92 & 218.60 & 287.37 & 582.64 & 172.70 \\
\hline $\mathrm{C}_{23}, \mathrm{GPa}$ & 175.21 & 189.98 & 158.07 & 177.25 & 149.62 & 80.29 & 171.47 & 317.91 & 224.33 \\
\hline $\mathrm{C}_{31}, \mathrm{GPa}$ & 196.39 & 194.78 & 175.24 & 176.92 & 148.94 & 110.44 & 148.31 & 140.81 & 153.35 \\
\hline $\mathrm{C}_{32}, \mathrm{GPa}$ & 175.21 & 189.98 & 158.07 & 177.25 & 149.62 & 80.29 & 171.47 & 317.91 & 224.34 \\
\hline $\mathrm{C}_{33}, \mathrm{GPa}$ & 323.42 & 349.57 & 281.49 & 298.15 & 238.29 & 166.38 & 266. & 236.22 & 314.95 \\
\hline $\mathrm{C}_{44}, \mathrm{GPa}$ & 201.06 & 185.16 & 152.90 & 142.32 & 120.55 & 155.45 & 162.46 & 151.29 & 139.82 \\
\hline $\mathrm{C}_{55}, \mathrm{GPa}$ & 152.61 & 183.58 & 168.16 & 165.50 & 141.12 & 151.66 & 135.70 & 130.06 & 98.25 \\
\hline $\mathrm{C}_{66}, \mathrm{GPa}$ & 191.21 & 190.51 & 164.92 & 160.14 & 136.67 & 150.31 & 169.68 & 167.65 & 146.50 \\
\hline
\end{tabular}

The considered orthorhombic crystals will be mechanically stable if the following conditions are satisfied [29]:

$$
\begin{gathered}
\mathrm{C}_{11}>0, \\
\mathrm{C}_{11} \mathrm{C}_{22}-\mathrm{C}_{12}{ }^{2}>0, \\
\mathrm{C}_{11} \mathrm{C}_{22} \mathrm{C}_{33}+\mathrm{C}_{12} \mathrm{C}_{13} \mathrm{C}_{23}-\mathrm{C}_{11} \mathrm{C}_{23}{ }^{2}-\mathrm{C}_{22} \mathrm{C}_{13}{ }^{2}-\mathrm{C}_{33} \mathrm{C}_{12}{ }^{2}>0 \\
\mathrm{C}_{44}>0, \\
\mathrm{C}_{55}>0, \\
\mathrm{C}_{66}>0,
\end{gathered}
$$

The calculated elastic constants suggest the orthorhombic $\mathrm{Si}_{\mathrm{x}} \mathrm{Cr}_{1-\mathrm{x}} \mathrm{CoNiFe}$ structure is mechanically stable at all the considered concentrations $(\mathrm{x}=12.5 \%, 25 \%, 37.5 \%$, and $50 \%)$ of Si impurities which replace $\mathrm{Cr}$. In the case of Co substitution by $\mathrm{Si}$, the orthorhombic $\mathrm{Si}_{\mathrm{y}} \mathrm{CrCo}_{1-\mathrm{y}} \mathrm{NiFe}$ structure is stable at 
the Si concentration of $\mathrm{y}=12.5 \%, 25 \%$, and $37.5 \%$, while at $\mathrm{y}=50 \%$ the crystal is mechanically unstable.

The Voigt [30] and the Reuss approximation [31] are used for the calculation of a polycrystalline bulk modulus $K$ and shear modulus $G$. The Voigt bulk moduli $K_{V}$ and shear moduli $G_{V}$ of an orthorhombic crystal are given by

$$
\begin{gathered}
K_{V}=\frac{1}{9}\left(\mathrm{C}_{11}+\mathrm{C}_{22}+\mathrm{C}_{33}+2 \mathrm{C}_{12}+2 \mathrm{C}_{13}+2 \mathrm{C}_{23}\right), \\
G_{V}=\frac{1}{15}\left(\mathrm{C}_{11}+\mathrm{C}_{22}+\mathrm{C}_{33}+3 \mathrm{C}_{44}+3 \mathrm{C}_{55}+3 \mathrm{C}_{66}-\mathrm{C}_{12}-\mathrm{C}_{13}-\mathrm{C}_{23}\right),
\end{gathered}
$$

The Reuss bulk moduli $K_{R}$ and shear moduli $G_{R}$ moduli are given by

$$
\begin{gathered}
K_{R}=\frac{1}{\left(S_{11}+S_{22}+S_{33}\right)+2\left(S_{12}+S_{13}+S_{23}\right)^{\prime}}, \\
G_{R}=\frac{15}{4\left(S_{11}+S_{22}+S_{33}\right)-4\left(S_{12}+S_{13}+S_{23}\right)+3\left(S_{44}+S_{55}+S_{66}\right)},
\end{gathered}
$$

where $S_{i j}$ are the elastic compliance constants and are given by $C_{i j}{ }^{-1}$.

According to the Hill [32] approach, the effective bulk moduli $K$ and shear moduli $G$ which show the resistivity of a material to a volume change and to a shape change, respectively, are calculated as an arithmetic average of $K_{V}$ and $K_{R}$ and $G_{V}$ and $G_{R}$, respectively:

$$
\begin{aligned}
& K=\frac{K_{V}+K_{R}}{2}, \\
& G=\frac{G_{V}+G_{R}}{2},
\end{aligned}
$$

The Young's modulus $E$ and Poisson's ratio $v$ can be given by

$$
\begin{aligned}
& E=\frac{9 K G}{3 K+G}, \\
& v=\frac{3 K-2 G}{2(3 K+G)} .
\end{aligned}
$$

The calculated bulk modulus $K$, shear modulus $G$, Young's modulus $E$, and Poisson's ratio $v$ of orthorhombic $\mathrm{Si}_{\mathrm{x}} \mathrm{Cr}_{1-\mathrm{x}} \mathrm{CoNiFe}$ and $\mathrm{Si}_{\mathrm{y}} \mathrm{CrCo}_{1-\mathrm{y}} \mathrm{NiFe}$ are given in Table 3.

The ductility and brittleness of materials are characterized by the Pugh's ratio [33] which is the ratio between the shear modulus and the bulk modulus $(G / K)$. The critical value of the $G / K$ ratio, below which the material becomes brittle, is 0.5 .

According to Table 3 for the case when $\mathrm{Cr}$ substituted by $\mathrm{Si}$, the $G / K$ ratio slightly increases from 0.54 to 0.56 with an increase of the concentration of Si dopants from $0 \%$ to $12.5 \%$. Further increase of the concentration of Si dopants from $12.5 \%$ to $50 \%$. leads to a decrease of the $G / K$ ratio from 0.56 to 0.49 . However, the $G / K$ ratio exudes the value at which the material becomes brittle only at the $\mathrm{S}$ concentration of $50 \%$ and above. In case of Co substitution by $\mathrm{Si}$, the $G / K$ ratio increases to 0.75 at the Si concentration of $12.5 \%$, and decreases to 0.54 and 0.43 at the Si concentration of $25 \%$ and $37.5 \%$, respectively.

According to "Frantsevich rule", materials with $v \leq 0.33$ are brittle and those with $v \geq 0.33$ are ductile [34]. Based on this criterion, it can be concluded that CrCoNiFe with $v=0.27$ is brittle, that result is well agreed with experimental data [35] In case of $\mathrm{Cr}$ to $\mathrm{Si}$ substitution, the brittleness of $\mathrm{Si}_{\mathrm{x}} \mathrm{Cr}_{1-\mathrm{x}} \mathrm{CoNiFe}$ crystals slightly decreases but still exists as $v \leq 0.33$. Similarly, for the $\mathrm{Si}_{\mathrm{x}} \mathrm{CrCo}_{1-\mathrm{x}} \mathrm{NiFe}$, even though an increase of the $\mathrm{Si} / \mathrm{Co}$ ratio leads to an increase of $v$, the crystal remains brittle.

Table 3. The Voigt, Reuss, and Hill bulk moduli $K_{V}, K_{R}$, and $K$ and shear moduli $G_{V}, G_{\mathrm{R}}$, and $G$, Young's modulus $E$, Poisson's ratio $v$, and Pugh's ratio of $\mathrm{Si}_{\mathrm{x}} \mathrm{Cr}_{1-\mathrm{x}} \mathrm{CoNiFe}$ and $\mathrm{Si}_{\mathrm{y}} \mathrm{CrCo}_{1-\mathrm{y}} \mathrm{NiFe}$ crystals.

$K_{V}, \mathrm{GPa} \quad K_{R}, \mathrm{GPa} \quad K, \mathrm{GPa} \quad G_{V}, \mathrm{GPa} \quad G_{\mathrm{R}}, \mathrm{GPa} \quad G, \mathrm{GPa} \quad E, \mathrm{GPa} \quad v \quad G / K$




\begin{tabular}{|c|c|c|c|c|c|c|c|c|c|}
\hline $\mathrm{CrCoNiFe}$ & 246.36 & 243.81 & 245.09 & 143.15 & 123.62 & 133.38 & 338.7 & 0.27 & 0.54 \\
\hline \multicolumn{10}{|c|}{$\mathrm{Si}_{\mathrm{x}} \mathrm{Cr}_{1-\mathrm{x}} \mathrm{CoNiFe}$} \\
\hline$x=12.5$ & 247.20 & 246.97 & 247.08 & 147.70 & 129.32 & 138.51 & 350.11 & 0.26 & 0.56 \\
\hline$x=25$ & 216.65 & 214 & 215.33 & 124.68 & 104.44 & 114.56 & 291.91 & 0.27 & 0.53 \\
\hline$x=37.5$ & 222.05 & 221.61 & 221.83 & 122.65 & 105.61 & 114.13 & 292.26 & 0.28 & 0.51 \\
\hline$x=50$ & 195.76 & 191.58 & 193.67 & 103.63 & 87.891 & 95.76 & 246.64 & 0.29 & 0.49 \\
\hline \multicolumn{10}{|c|}{$\mathrm{Si}_{\mathrm{y}} \mathrm{CrCo}_{1-\mathrm{y}} \mathrm{NiFe}$} \\
\hline$y=12.5$ & 144.77 & 131.58 & 138.17 & 115.90 & 91.75 & 103.83 & 249.09 & 0.20 & 0.75 \\
\hline$y=25$ & 205.20 & 203.90 & 204.55 & 121.43 & 99.947 & 110.69 & 281.32 & 0.27 & 0.54 \\
\hline$y=37.5$ & 282.82 & 155.27 & 219.04 & 117.80 & 69.25 & 93.52 & 245.61 & 0.31 & 0.43 \\
\hline
\end{tabular}

Cauchy pressure is another important parameter when considering whether the material has metallic or angular bonds to predict if it is ductile or brittle [35]. For the considered orthorhombic systems, the Cauchy pressure is defined as $\mathrm{C}_{23}-\mathrm{C}_{44}$ for the (100) plane, $\mathrm{C}_{13}-\mathrm{C}_{55}$ for the (010) plane, and $\mathrm{C}_{12}-\mathrm{C}_{66}$ for the (001) plane. The calculated values of the Cauchy pressure for the considered crystals are presented in Table 4. According to obtained single crystal elastic constants, for pure $\mathrm{CrCoNiFe}$, the calculated value is $-25.85 \mathrm{GPa}$ for the pressure $\left(\mathrm{C}_{23}-\mathrm{C}_{44}\right), 43.78 \mathrm{GPa}$ for the pressure $\left(\mathrm{C}_{13}-\mathrm{C}_{55}\right)$, and $5.41 \mathrm{GPa}$ for the pressure $\left(\mathrm{C}_{12}-\mathrm{C}_{66}\right)$. The results indicate that the bonding in the (100) plane has a strong metallic character, whereas those in the (010) and (001) planes have an angular character. The presence of $12.5 \%$ of $\mathrm{Si}$ substitute of $\mathrm{Cr}$ changes the bonding nature of $\mathrm{CrCoNiFe}$, in such a way that (001) plane has a strong metallic character, while in the (010) and (100) planes bindings are of an angular character. In the case when Co is replaced by $\mathrm{Si}$ (concentration of $12.5 \%$ ) there is a strong metallic bonding in all three (100), (010), and (001) planes. The further increase of Si concentration upon Co and Cr substitution by $\mathrm{Si}$ weakens the bonding within crystals as a strong angular character of bonding in all planes is observed.

Table 4. The Cauchy pressures (in GPa) of $\mathrm{Si}_{\mathrm{x}} \mathrm{Cr}_{1-\mathrm{x}} \mathrm{CoNiFe}$ and $\mathrm{Si}_{\mathrm{y}} \mathrm{CrCo}_{1-\mathrm{y}} \mathrm{NiFe}$ crystals, where $\mathrm{x}$ and $\mathrm{y}$ are the concentration of element.

\begin{tabular}{c|c|cccc|ccc}
\hline & CrCoNiFe & \multicolumn{3}{|c|}{$\mathrm{Si}_{\mathrm{x}} \mathrm{Cr}_{1-\mathrm{x}} \mathrm{CoNiFe}$} & \multicolumn{3}{|c}{$\mathrm{Si}_{\mathrm{y}} \mathrm{Co}_{1-\mathrm{y}} \mathrm{CrNiFe}$} \\
\hline & $\mathrm{x}=0$ & $\mathrm{x}=12.5$ & $\mathrm{x}=25$ & $\mathrm{x}=37.5$ & $\mathrm{x}=50$ & $\mathrm{y}=12.5$ & $\mathrm{y}=25$ & $\mathrm{y}=37.5$ \\
\hline $\begin{array}{c}(100) \\
\text { plane }\end{array}$ & -25.85 & 4.82 & 5.17 & 34.93 & 29.07 & -75.16 & 9.01 & 166.62 \\
\hline $\begin{array}{c}(010) \\
\text { plane }\end{array}$ & 43.78 & 11.2 & 7.08 & 11.42 & 7.82 & -41.22 & 12.61 & 10.75 \\
\hline $\begin{array}{c}(001) \\
\text { plane }\end{array}$ & 5.41 & -12.95 & 14.28 & 6.57 & 32.23 & -28.82 & -13.16 & 82.11 \\
\hline
\end{tabular}

Elastic anisotropy. The formation and propagation of micro-cracks in a material are directly correlated with the elastic anisotropy of the crystal. The elastic anisotropy can be measured by shear anisotropic factors $A_{\mathrm{a}}, A_{\mathrm{b}}$, and $A_{\mathrm{c}}$, where $a, b$, and $c$ correspond to different crystallographic planes $\{100\},\{010\}$, and $\{001\}$. For the orthorhombic $\mathrm{CrCoNiFe}$ and its Si-containing derivatives, shear anisotropic factors $A_{\mathrm{a}}, A_{\mathrm{b}}$, and $A_{\mathrm{c}}$ can be calculated as follows [36]:

$$
A_{a}=\frac{4 C_{44}}{\left(C_{11}+C_{33}-2 C_{13}\right)}
$$




$$
\begin{aligned}
& A_{b}=\frac{4 C_{55}}{\left(C_{22}+C_{33}-2 C_{23}\right)}, \\
& A_{c}=\frac{4 C_{66}}{\left(C_{11}+C_{22}-2 C_{12}\right)} .
\end{aligned}
$$

The shear anisotropy factors $A_{\mathrm{a}}, A_{\mathrm{b}}$, and $A_{\mathrm{c}}$ as a function of the $\mathrm{Si}$ concentration for $\mathrm{Si}_{\mathrm{x}} \mathrm{Cr}_{1-\mathrm{x}} \mathrm{CoNiFe}$ and $\mathrm{Si}_{\mathrm{y}} \mathrm{CrCo}_{1-y} \mathrm{NiFe}$ crystals are plotted in Figure $2 \mathrm{a}$. The elastic anisotropy in compressibility $\left(A_{B}\right)$ and shear $\left(A_{G}\right)$ can be expressed as follows [37]:

$$
\begin{aligned}
& A_{B}=\frac{K_{V}-K_{R}}{K_{V}+K_{R}}, \\
& A_{G}=\frac{G_{V}-G_{R}}{G_{V}+G_{R}} .
\end{aligned}
$$

$A_{B}$ and $A_{G}$ as a function of the $\mathrm{Si}$ concentration for $\mathrm{Si}_{\mathrm{x}} \mathrm{Cr}_{1-\mathrm{x}} \mathrm{CoNiFe}$ and $\mathrm{Si}_{\mathrm{y}} \mathrm{Co}_{1-\mathrm{y}} \mathrm{CrNiFe}$ crystals are plotted in Figure $2 b$.

For an isotropic crystal, the shear anisotropy factors are equal to 1 , the deviation of the shear anisotropy factors from 1 is the degree of elastic anisotropy. From Figure $2 \mathrm{a}$ it is seen that the values of $A_{\mathrm{a}}, A_{\mathrm{b}}$, and $A_{\mathrm{c}}$ are all exceeded 1 for $\mathrm{CrCoNiFe}$ and $A_{\mathrm{a}}=2.53$ has the largest absolute deviation from 1 , which indicates that the shear anisotropy for the $\{100\}$ plane is the strongest. An introduction of Si as a substitute for $\mathrm{Cr}$ or Co increases the deviation of $A_{\mathrm{c}}$ and decreases the deviation of $A_{\mathrm{a}}$. Therefore, the shear anisotropy for the $\{001\}$ plane becomes predominant.

In addition, $A_{\mathrm{B}}$ and $A_{\mathrm{G}}$ anisotropy factors are calculated. The deviation of the values of $A_{\mathrm{B}}$ and $A_{\mathrm{G}}$ from 0 is a measure of the anisotropic degree of the crystal. From Figure $2 b$ it is seen that these values of $A_{\mathrm{B}}$ and $A_{\mathrm{G}}$ are nonzero and positive, and the value of $A_{\mathrm{G}}$ is significantly larger than that of $A_{\mathrm{B}}$ for $\mathrm{CrCoNiFe}$. The substitution of $\mathrm{Cr}$ by $\mathrm{Si}$ leads to a fluctuation of the value of $A_{\mathrm{B}}$ around 0 , while the value of $A_{\mathrm{G}}$ is significantly larger than that of $A_{\mathrm{B}}$. The obtained results suggest that $\mathrm{CrCoNiFe}$ and its $\mathrm{Si}$ containing derivatives possess high elastic anisotropy and a high anisotropic degree of shear modulus. Noticeably, the bulk modulus of $\mathrm{CrCoNiFe}$ is isotropic and the presence of Si instead of $\mathrm{Cr}$ does not affect its isotropy.

(a)
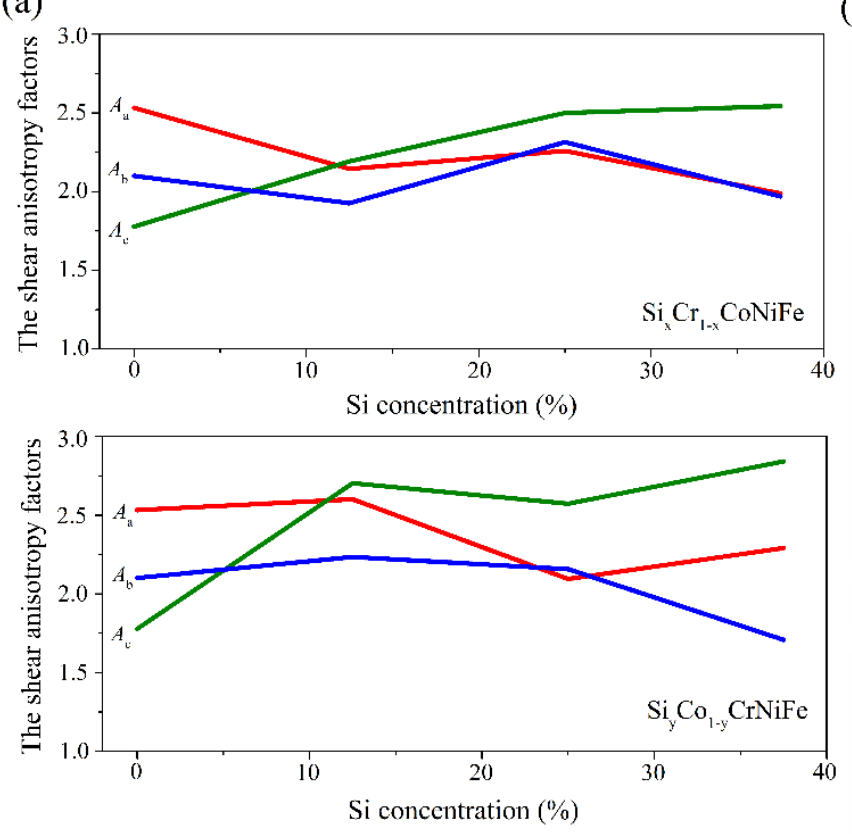

(b)
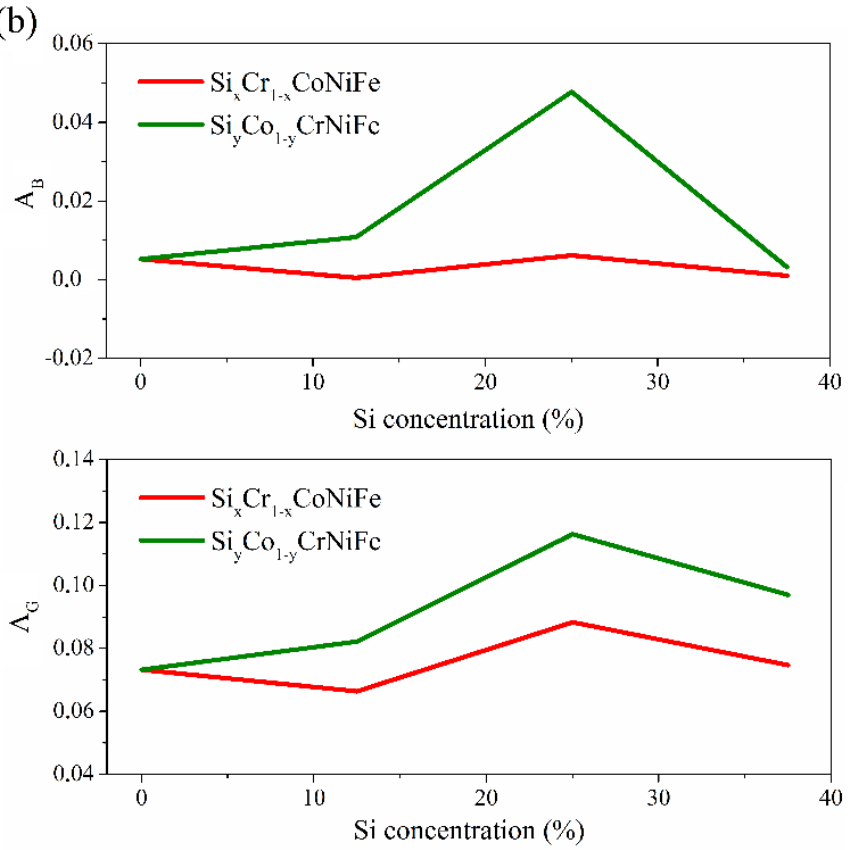

Figure 2. (a) The shear anisotropy factors $A_{\mathrm{a}}, A_{\mathrm{b}}$, and $A_{\mathrm{c}}$ and (b) $A_{B}$ and $A_{G}$ as a function of the $\mathrm{Si}$ concentration for $\mathrm{Si}_{\mathrm{x}} \mathrm{Cr}_{1-\mathrm{x}} \mathrm{CoNiFe}$ and $\mathrm{Si}_{\mathrm{y}} \mathrm{CrCo}_{1-\mathrm{y}} \mathrm{NiFe}$ crystals.

The orientation dependence of Young's modulus can also illustrate the elastic anisotropy of the crystals. For an orthorhombic crystal, the Young's modulus in any orientation is expressed as [38] 


$$
\frac{1}{E}=S_{11} \alpha^{4}+\left(2 S_{12}+S_{66}\right) \alpha^{2} \beta^{2}+S_{22} \beta^{4}+\left(2 S_{23}+S_{44}\right) \beta^{2} \gamma^{2}+S_{33} \gamma^{4}+\left(2 S_{13}+S_{55}\right) \alpha^{2} \gamma^{2}
$$

where $\alpha=\sin \theta \cos \varphi, \beta=\sin \theta \sin \varphi$, and $\gamma=\cos \varphi$ are the direction $\operatorname{cosines~under~the~spherical~coordinates.~}$ The orientation dependence of Young's modulus in the $x y, y z$, and $x z$ planes for CrCoNiFe are shown in Figure 3a-c, respectively. The plots of orientation dependence of Young's modulus in different planes at different concentrations of $\mathrm{Si}$ for $\mathrm{Si}_{\mathrm{x}} \mathrm{Cr}_{1-\mathrm{x}} \mathrm{CoNiFe}$ and $\mathrm{Si}_{\mathrm{y}} \mathrm{CrCo}_{1-\mathrm{y}} \mathrm{NiFe}$ crystals are shown in Figures 4 and 5, respectively. It is seen that $\mathrm{CrCoNiFe}$ has elastic anisotropy because the orbit of Young's modulus in all planes is not a perfect circle. Upon substitution of $\mathrm{Cr}$ by Si the elastic anisotropy of the crystal is not much affected and the Young's modulus of the (100) plane has a stronger anisotropic character in comparison with other planes. The substitution of Co by $\mathrm{Si}$ leads to remarkable changes in Young's modulus in different planes. At the concentration of Si of $12.5 \%$ the Young's modulus of the (100) plane has a stronger anisotropic character in comparison with other planes while at the concentration of Si of $25 \%$ the Young's modulus of the (001) plane is more anisotropic. An increase of Si concentration to $50 \%$ drastically reduces the stiffness of the crystal with a Young's modulus strongly anisotropic in all planes.

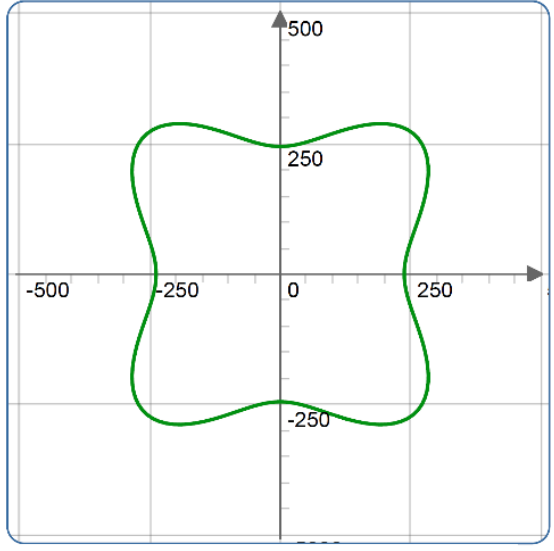

Young's modulus in (xy) plane

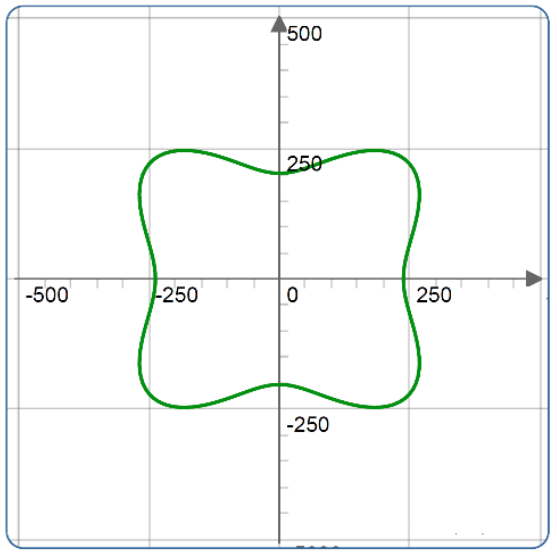

Young's modulus in $(x z)$ plane

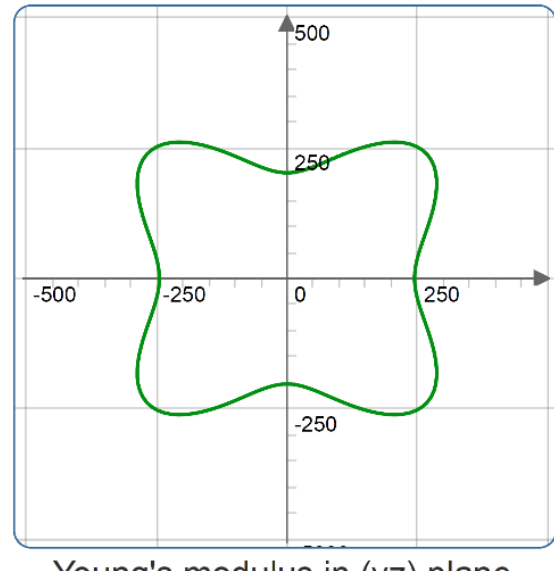

Young's modulus in (yz) plane

Figure 3. The projections of Young's modulus in the $x y, x z$, and $y z$ planes for pure CrCoNiFe.

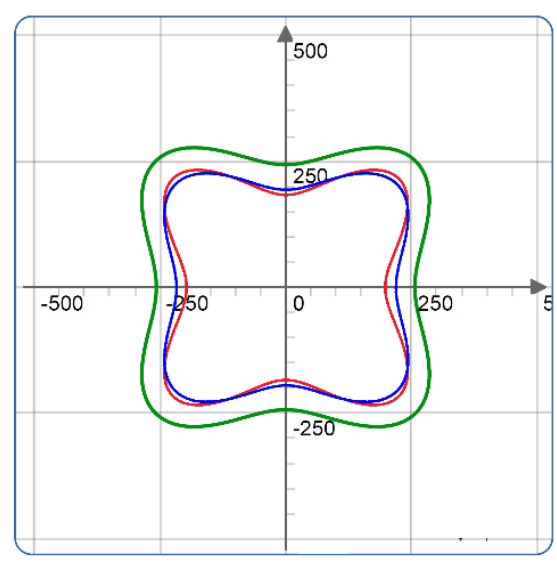

Young's modulus in (xy) plane

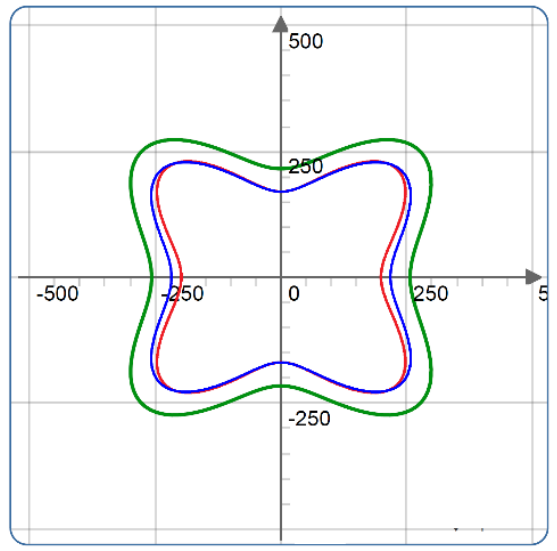

Young's modulus in $(x z)$ plane

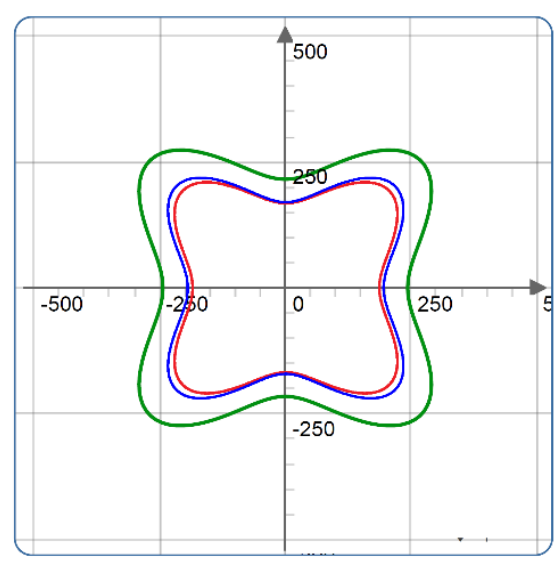

Young's modulus in (yz) plane

Figure 4. The projections of Young's modulus in the $x y, x z$, and $y z$ planes for $\mathrm{Si}_{\mathrm{x}} \mathrm{Cr}_{1-\mathrm{x}} \mathrm{CoNiFe}$ at the concentration of Si of $12.5 \%$ (green line), $25 \%$ (red line), and $37.5 \%$ (blue line). 


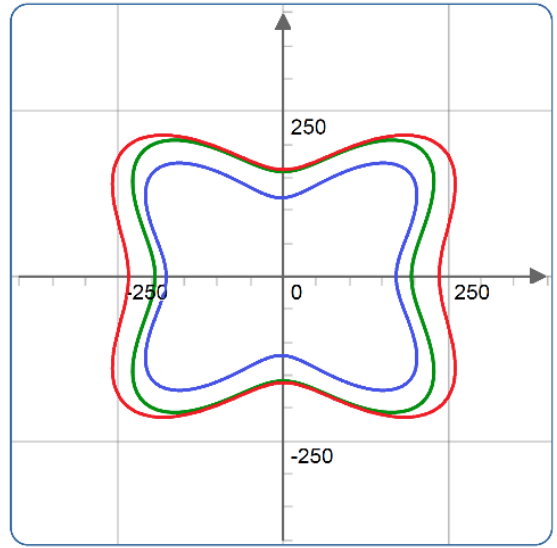

Young's modulus in (xy) plane

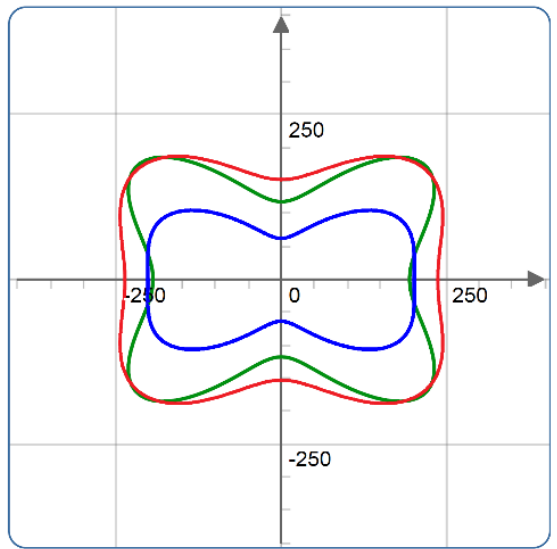

Young's modulus in $(x z)$ plane

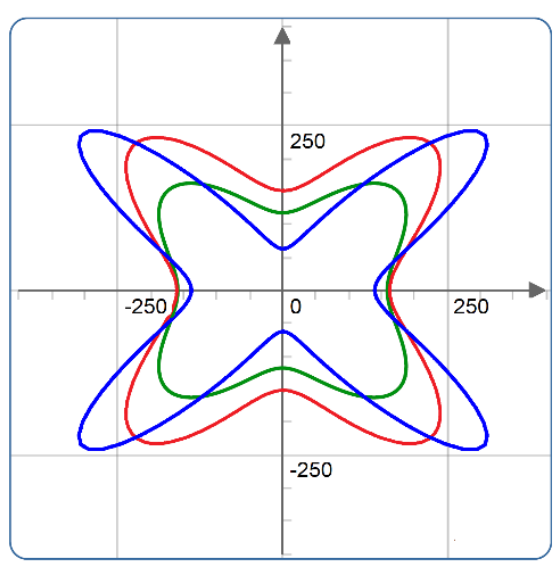

Young's modulus in (yz) plane

Figure 5. The projections of Young's modulus in the $x y, x z$, and $y z$ planes for $\mathrm{Si}_{\mathrm{y}} \mathrm{CrCo}_{1-\mathrm{y}} \mathrm{NiFe}$ at the concentration of Si of $12.5 \%$ (green line), $25 \%$ (red line), and $37.5 \%$ (blue line).

Electronic structure. To investigate changes in the electronic structure of $\mathrm{CrCoNiFe}$ upon the introduction of Si atoms, the density of states (DOS) and partial density of states (PDOS) of each element are calculated. For the case when $\mathrm{Cr}$ atoms are substituted by Si atoms, Figures 6a-c show DOS of each element for the crystals $\mathrm{CrCoNiFe}, \mathrm{CrCoNiFe}$ with $12.5 \%$ of $\mathrm{Si}$, and $\mathrm{CrCoNiFe}$ with $25 \%$ of $\mathrm{Si}$, respectively. The total DOSs of the three crystals exhibit metallic feature. In all cases, the bonding states are dominated by $\mathrm{Cr}-d$, $\mathrm{Co}-d, \mathrm{Ni}-d, \mathrm{Fe}-d$, and $\mathrm{Si}-s, p$. A strong hybridization between $\mathrm{Cr}, \mathrm{Co}, \mathrm{Ni}$, and $\mathrm{Fe}$ states implies that bonds between the atoms of these elements have a covalent character. The calculated DOSs at the Fermi level demonstrate the stability of the structures as the smaller value of DOSs at the Fermi level implies higher stability [39]. From Figure 6 it can be seen that the crystal without Si substitutes is characterized by lower density at the Fermi level compare to these with Si substitutes. With increasing the Si concentration, the density of energy states at the Fermi level is slightly increasing. These results suggest the crystal without Si substitutes suggest higher stability of that structure compared to that of with Si which is in line with our results on the mechanical stability of these structures. It should be noted that the decrease of the total DOS is caused by the decrease of intensity of Cr states. For the Si, there are both $s$ and $p$ states with the predomination of $s$ states. According to Figure $6 \mathrm{~b}$, at low concentration of $\mathrm{Si}(12.5 \%)$, there is no hybridization between the main states of the crystal and Si states. Therefore, non-covalent interaction between $\mathrm{Si}$ and other atoms is predicted. The higher concentration of Si substitutes leads to a decrease of intensity of $s$-states of Si and a hybridization of $p$-states of Si with the states of other atoms. That may indicate covalent interaction between Si and other atoms.

For the case when Co atoms are substituted by Si atoms, Figures 7a-c show DOS of each element for the crystals $\mathrm{CrCoNiFe}, \mathrm{CrCoNiFe}$ with $12.5 \%$ of $\mathrm{Si}$, and $\mathrm{CrCoNiFe}$ with $25 \%$ of $\mathrm{Si}$, respectively. The total DOSs of the three crystals also possess metallic nature. Comparing with these of pure $\mathrm{CrCoNiFe}$ alloy, the intensity of DOSs at the Fermi level of the $\mathrm{Si}_{\mathrm{x}} \mathrm{Cr}_{1-\mathrm{x}} \mathrm{CoNiFe}$ alloy lower at the Si concentration of $25 \%$ and significantly lower at the Si concentration of $12.5 \%$. That may be due to a decrease of intensity of Co states which is compensated by an increase of intensity of Fe states as shown in Figure 7. Such a difference in the nature of DOSs of CrCoNiFe with Co substituted by Si compared to that of $\mathrm{CrCoNiFe}$ with $\mathrm{Cr}$ substituted by Si can explain the observed higher stability (lower formation energy) of $\mathrm{CrCoNiFe}$ with Co substituted by Si. For the nature of Si bonding, according to Figure 7b, at low concentration of $\mathrm{Si}(12.5 \%)$, the is no hybridization between the main states of the crystal and Si states. Hence, non-covalent bonding between $\mathrm{Si}$ and other atoms is predicted. The higher concentration of $\mathrm{Si}$ substitutes leads to a decrease of intensity of $s$-states of $\mathrm{Si}$ and a hybridization of $p$-states of Si with the states of other atoms. That may indicate covalent interaction between Si and other atoms. 
(a)
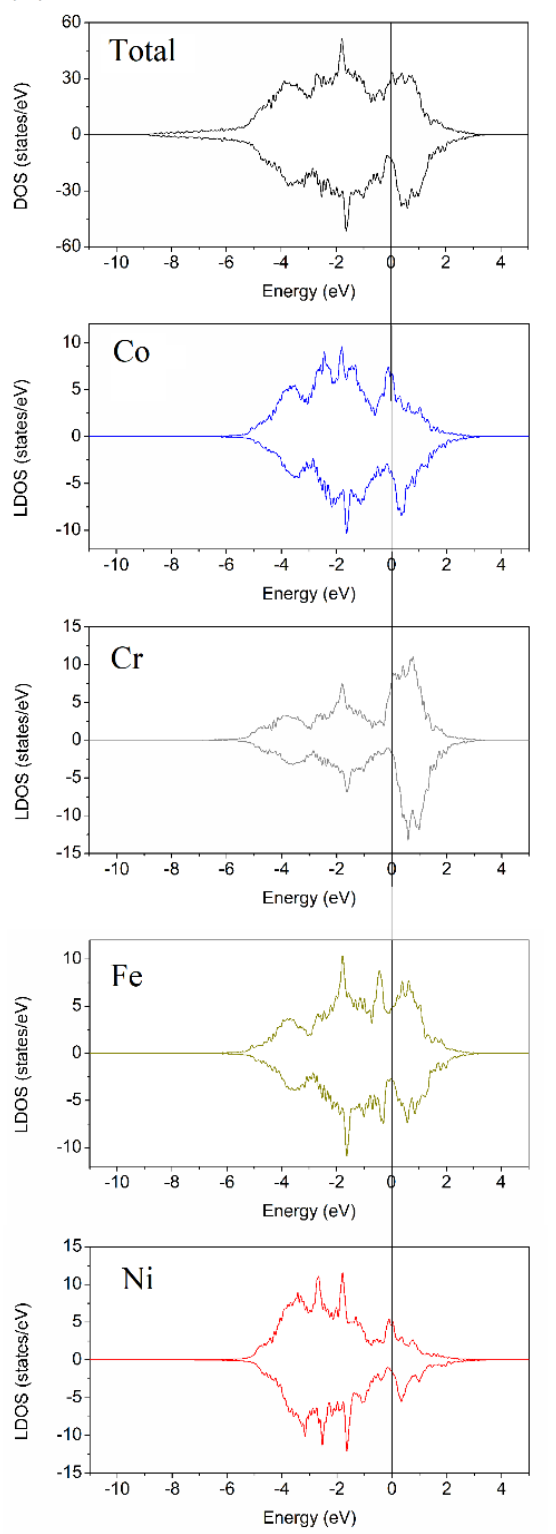

(b)
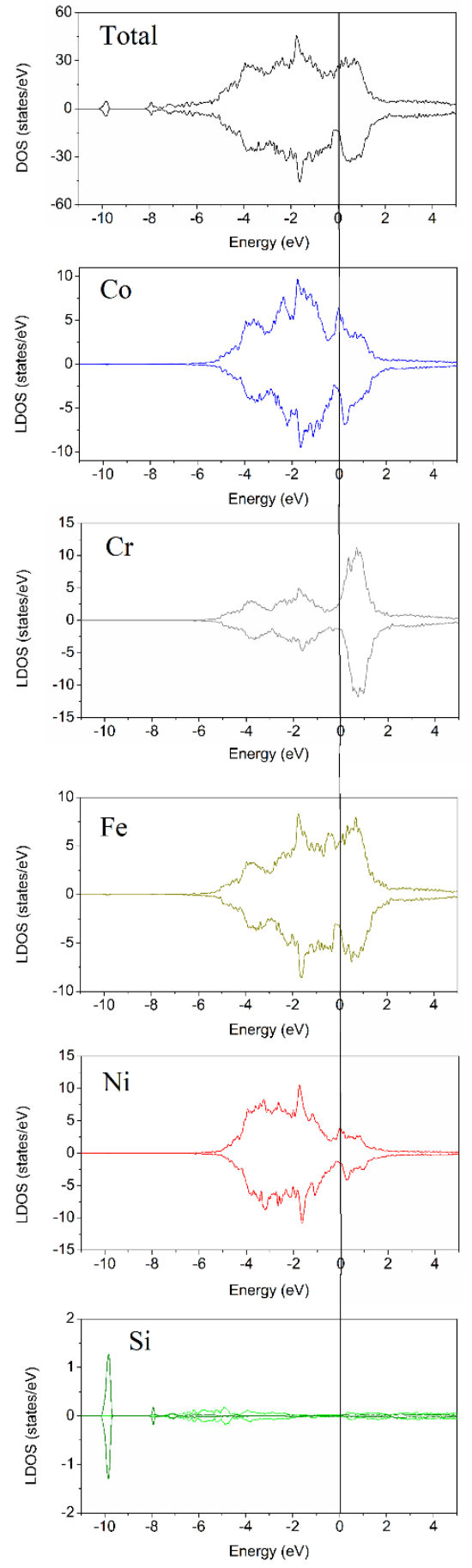

(c)
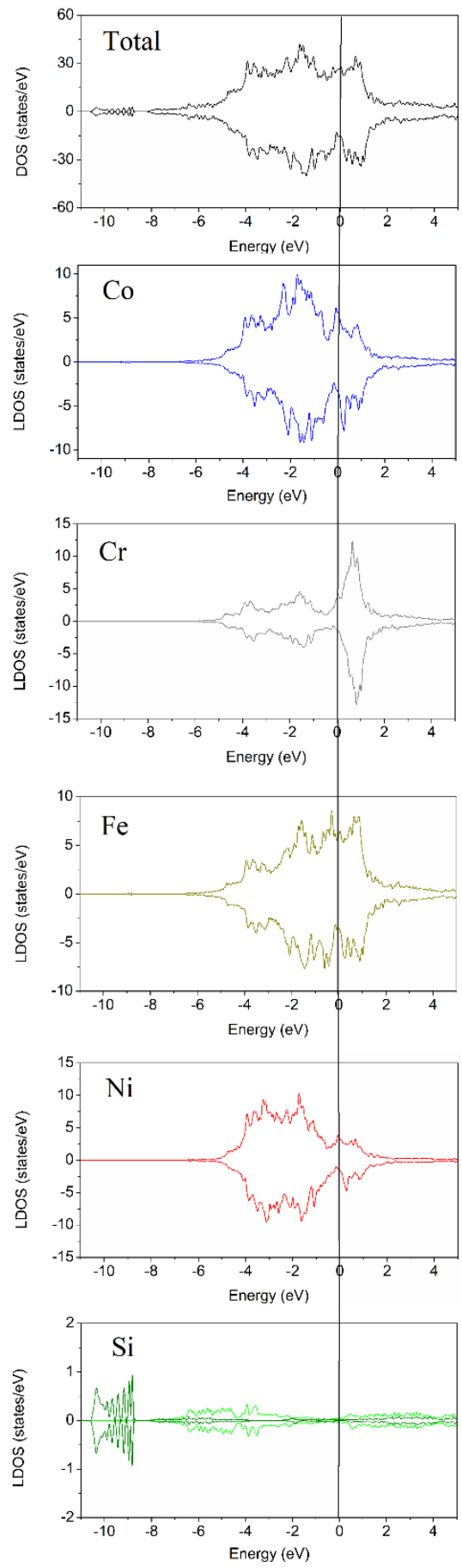

Figure 6. DOS and PDOS of elements of $\mathrm{Si}_{\mathrm{x}} \mathrm{Cr}_{1-\mathrm{x}} \mathrm{CoNiFe}$ at the concentration of $\mathrm{Si}$ of (a) $0 \%$, (b)12.5\%, and (c) $25 \%$. 
(a)
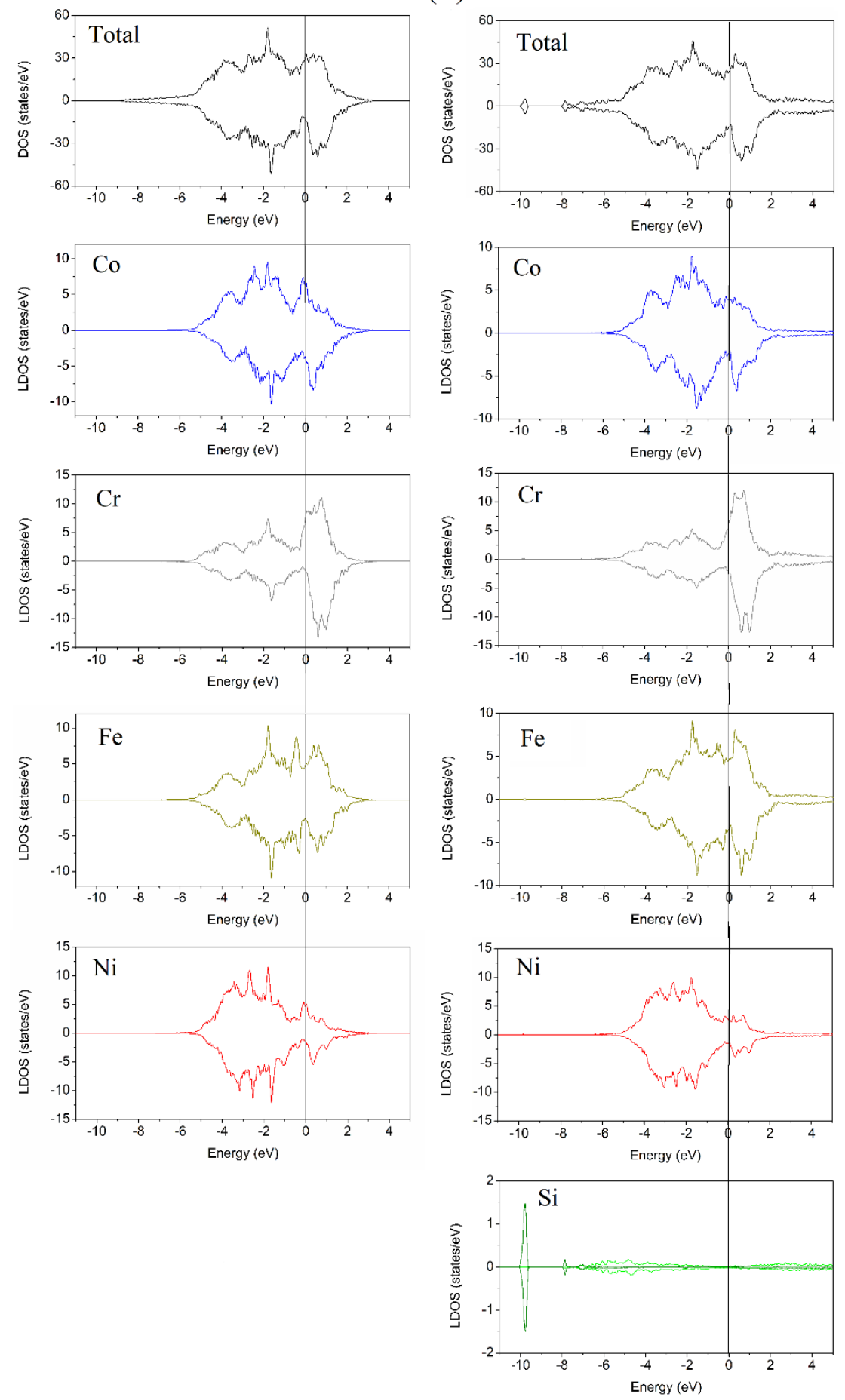

(c)
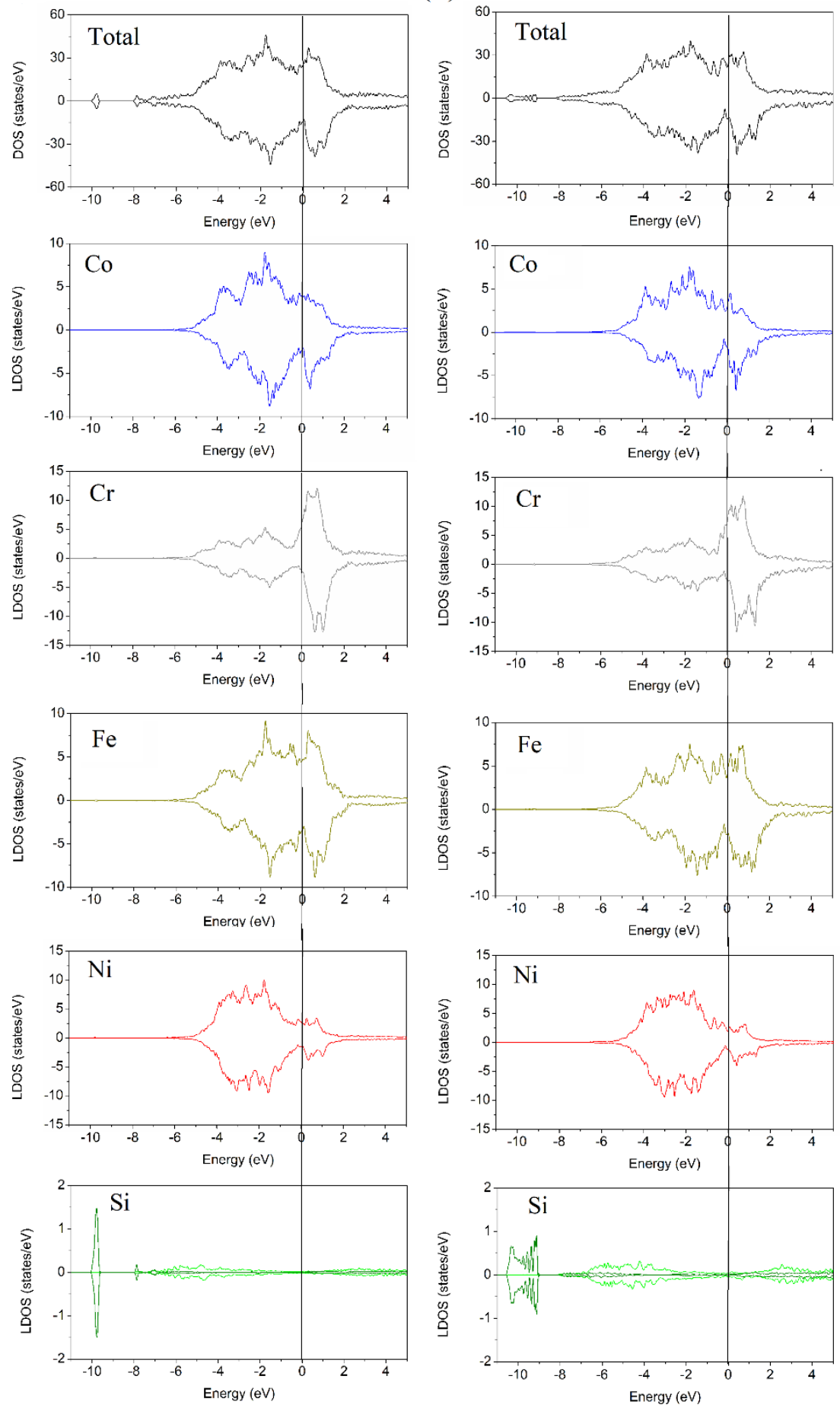

Figure 7. DOS and PDOS of elements of $\mathrm{Si}_{y} \mathrm{CrCo}_{1-y} \mathrm{NiFe}$ at the concentration of $\mathrm{Si}$ of (a) $0 \%$, (b)12.5\%, and (c) $25 \%$.

To get deeper understanding about the further reveal the bonding feature, characteristics, the crystal orbital overlap population (COOP) analysis is conducted for $\mathrm{CrCoNiFe}, \mathrm{Si}_{0.125} \mathrm{CrCo}_{0.875} \mathrm{NiFe}$, and $\mathrm{Si}_{0.125} \mathrm{Cr}_{0.875} \mathrm{CoNiFe}$ as shown in Figure 8a-c, respectively. The negative COOP represents the occupation of the bonding state while the positive value implies antibonding [40]. It is found that there are more positive values (anti-bonding states) in $\mathrm{CrCoNiFe}$ than in both $\mathrm{Si}_{0.125} \mathrm{CrCo}_{0.875} \mathrm{NiFe}$, and $\mathrm{Si}_{0.125} \mathrm{Cr}_{0.875} \mathrm{CoNiFe}$. Therefore, $\mathrm{Si}_{0.125} \mathrm{CrCo}_{0.875} \mathrm{NiFe}$, and $\mathrm{Si}_{0.125} \mathrm{Cr}_{0.875} \mathrm{CoNiFe}$ possess higher stability comparing to $\mathrm{CrCoNiFe}$, which is consistent with the results on the formation energy calculation. In 
addition, there are less positive values (anti-bonding states) of Si-Co bonds (a peak at -9.5 eV in Figure 8d) in $\mathrm{Si}_{0.125} \mathrm{CrCo}_{0.875} \mathrm{NiFe}$ than those of $\mathrm{Si}-\mathrm{Cr}$ bonds (a peak at $\sim-9.5 \mathrm{eV}$ in Figure 8e) in $\mathrm{Si}_{0.125}$ $\mathrm{Cr}_{0.875} \mathrm{CoNiFe}$ which further explain the higher stability of $\mathrm{Si}_{0.125} \mathrm{CrCo}_{0.875} \mathrm{NiFe}$ comparing to $\mathrm{Si}_{0.125}$ $\mathrm{Cr}_{0.875} \mathrm{CoNiFe}$.
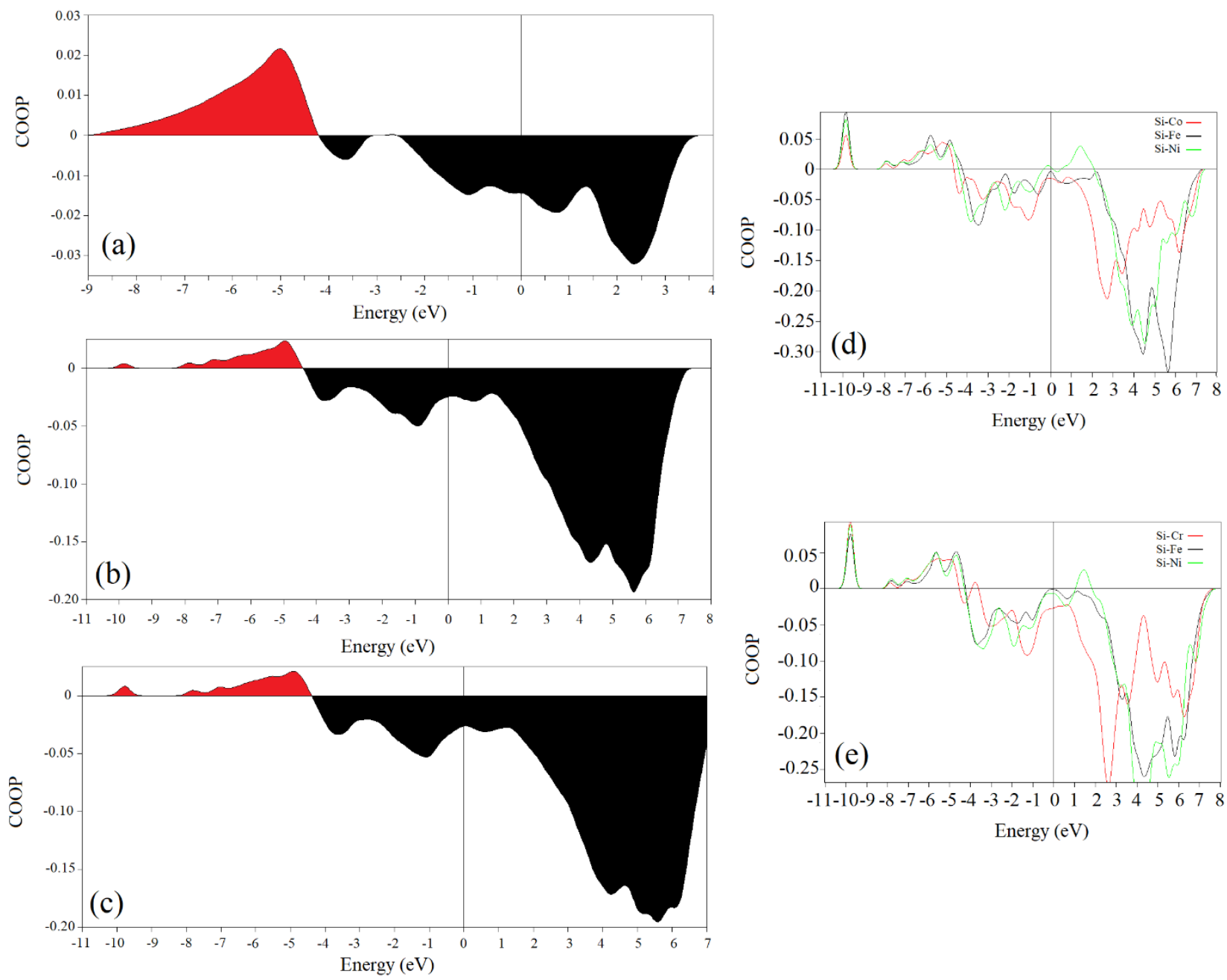

Figure 8. The average COOP of (a) $\mathrm{CrCoNiFe}$, (b) $\mathrm{Si}_{0.125} \mathrm{CrCo}_{0.875} \mathrm{NiFe}$, and (c) $\mathrm{Si}_{0.125} \mathrm{Cr}_{0.875} \mathrm{CoNiFe}$. The COOP for $\mathrm{Si}$ in (d) $\mathrm{Si}_{0.125} \mathrm{CrCo}_{0.875} \mathrm{NiFe}$ and (e) $\mathrm{Si}_{0.125} \mathrm{Cr}_{0.875} \mathrm{CoNiFe}$. The Fermi level is set at zero and marked by vertical black line.

To investigate the charge transfer within the CrCoNiFe crystal upon Si-doping, the Bader analysis [41] is conducted. Table 5 collects the charges of pure elemental components of the crystal together with the charges of each element within the crystal. In pure CrCoNiFe there is a strong charge transfer $(\sim 0.96$ $e$ per atom) from the $\mathrm{Cr}$ atoms mainly to the $\mathrm{Ni}$ and $\mathrm{Co}$ atoms. The substitution of $\mathrm{Cr}$ by $\mathrm{Si}$ decreases the loss of the charge by the $\mathrm{Cr}$ atoms ( 0.62-0.64 e per atom) while leads to the charge transfer from the $\mathrm{Si}$ atoms to the remaining atoms. An increase of the Si concentration lowers the charge redistribution within the crystal. The substitution of Co by Si also decreases the loss of the charge by the Cratoms ( $\sim 0.60 e$ per atom) and the redistribution of the charge within the crystal. In addition, at the Co position the $\mathrm{Si}$ lose rawer electrons compared to that at the position of $\mathrm{Cr}$. That also explains the significant difference in the nature of DOSs of $\mathrm{CrCoNiFe}$ with Co substituted by Si compared to that of $\mathrm{CrCoNiFe}$ with $\mathrm{Cr}$ substituted by Si as shown in Figures 6 and 7. 
Table 5. The charge distribution of pure and Si-doped CrCoNiFe.

\begin{tabular}{|c|c|c|c|c|c|}
\hline Element (charge) & Co $(9 e)$ & $\mathrm{Cr}(12 e)$ & $\mathrm{Fe}(14 e)$ & $\mathrm{Ni}(16 e)$ & $\mathrm{Si}(4 e)$ \\
\hline & \multicolumn{5}{|c|}{ Charge of each element in the structure, $e$} \\
\hline & Co & $\mathrm{Cr}$ & $\mathrm{Fe}$ & $\mathrm{Ni}$ & $\mathrm{Si}$ \\
\hline $\mathrm{CrCoNiFe}\left(2^{\times} 2^{\times} 2\right.$ supercell $)$ & 9.34 & 11.04 & 14.13 & 16.49 & - \\
\hline \multicolumn{6}{|l|}{$\mathrm{Si}_{\mathrm{x}} \mathrm{Cr}_{1-\mathrm{x}} \mathrm{CoNiFe}$} \\
\hline $\mathrm{x}=12.5$ & 9.14 & 11.38 & 14.10 & 16.37 & 3.74 \\
\hline$x=25$ & $\begin{array}{l}9.05- \\
9.15\end{array}$ & 11.34 & 14.05 & 16.39 & 3.77 \\
\hline \multicolumn{6}{|l|}{$\mathrm{Si}_{\mathrm{y}} \mathrm{CrCo}_{1-\mathrm{y}} \mathrm{NiFe}$} \\
\hline$y=12.5$ & 9.12 & 11.40 & 14.07 & 16.40 & 3.94 \\
\hline$y=25$ & 9.10 & 11.40 & 14.08 & 16.43 & 3.96 \\
\hline
\end{tabular}

Magnetic properties. To understand the preference of ferromagnetism (FM) over antiferromagnetism (AFM) of $\mathrm{CrCoNiFe}$ with $\mathrm{Si}$ addition the magnetic coupling energy, $\mathrm{dE}$ is calculated. The data is presented in Table 6 .

\begin{tabular}{|c|c|c|c|}
\hline \multicolumn{5}{|c|}{ Table 6. Magnetization energy (meV) of Si-doped CrCoNiFe. } \\
\hline Composition & FM & AFM & $\mathrm{dE}(\mathrm{meV})$ \\
\hline $\mathrm{Si}_{0.25} \mathrm{Cr}_{0.75} \mathrm{CoNiFe}$ & -240.457 & -240.48 & 0.625 \\
\hline $\mathrm{Si}_{0.125} \mathrm{Cr}_{0.875} \mathrm{CoNiFe}$ & -242.531 & -243.145 & 19.18 \\
\hline $\mathrm{Si}_{0.125} \mathrm{CrCo}_{0.875} \mathrm{NiFe}$ & -244.809 & -238.521 & -196.2 \\
\hline $\mathrm{Si}_{0.25} \mathrm{CrCo}_{0.75} \mathrm{NiFe}$ & -244.032 & -239.569 & -139.43 \\
\hline
\end{tabular}

The total energy is calculated by orienting spins along parallel and antiparallel directions and the magnetization energy/cell is calculated as,

$$
\mathrm{dE}=\left(E_{F M}-E_{A F M}\right) / \mathrm{N}
$$

where $E_{F M}$ is the total energy of the cell with the magnetic moments of all atoms initialized with positive values to obtain ferromagnetic configuration, while an antiferromagnetic configuration is simulated by initializing negative magnetic moments on some of the $\mathrm{Cr}$ and $\mathrm{Si}$ atoms. $\mathrm{N}$ is the total energy of atoms in the cell. From this definition, a negative value of $\mathrm{dE}$ indicates that FM is preferred and vice versa. It is seen that the increase of the concentration of $\mathrm{Si}$ dopants is leading to the stabilization of FM orientation. This indicates Si can effectively replace Co, by stabilizing FM orientation. This finding aligns with previous studies wherein change in Si concentration is related to the change in the saturation magnetization of the system [21]. It is also worthwhile to note that $\mathrm{Si}$ is the smallest atom, among all atoms, considered in the present study, with an atomic radius of $1.11 \AA$. Hence, once Si is substituted for other atoms, the volume of the cell decreases. This reduction in volume will be resulted in changes in the electron sharing and also affects the magnetic anisotropy of the system, which will result in 
reorientation of magnetic moments. This reorientation of magnetic moments by Si has also been observed in other materials such as Fe3Ge [42].

\section{Conclusions}

In this work the effect of $\mathrm{Co}$ and $\mathrm{Cr}$ substitution by $\mathrm{Si}$ in a $\mathrm{CrCoNiFe}$ high-entropy alloy on its structural stability, mechanical, electronic and magnetic properties is studied. It has been revealed that the structural stability of Si-doped $\mathrm{CrCoNiFe}$ is higher in case of the substitution of Co by Si compared to the case of the substitution of $\mathrm{Cr}$ by Si. Mechanical stability of Si-doped CrCoNiFe is predicted for the concentration of $\mathrm{Si}$ up to $37.5 \%$ if $\mathrm{Co}$ is replaced and up to $50 \%$ if $\mathrm{Cr}$ is replaced. From the calculated Pugh's ratio, Cauchy pressure, and Poisson's ratio, it is shown that the brittleness of CrCoNiFe slightly decreases with the substitution of $\mathrm{Cr}$ or Co with Si. It is also found that the Young's modulus of $\mathrm{CrCoNiFe}$ slightly increases in the case of substitution of $\mathrm{Cr}$ by $\mathrm{Si}$ at the concentration of $\mathrm{Si}$ of $12.5 \%$ while the higher concentrations of Si lead to the decrease of Young's modulus of CrCoNiFe. The replacement of $\mathrm{Co}$ by $\mathrm{Si}$ leads to a drastic decrease of the Young's modulus of $\mathrm{CrCoNiFe}$. According to electronic structure calculations, at a low Si concentration (12.5\%) a non-covalent interaction between $\mathrm{Si}$ and other atoms in Si-doped $\mathrm{CrCoNiFe}$ is observed while the higher concentration of $\mathrm{Si}$ substitutes leads to a covalent interaction between $\mathrm{Si}$ and other atoms in $\mathrm{Si}$-doped $\mathrm{CrCoNiFe}$. This is also confirmed by the distribution of charges at each atom obtained through the Bader analysis. In addition, Si can effectively replace Co by stabilizing the ferromagnetic moment of $\mathrm{CrCoNiFe}$. Therefore, it is proposed that $\mathrm{Si}$ can be a feasible alloying element for the modification of magnetic and electronic properties of $\mathrm{CrCoNiFe}$. On the other hand, $\mathrm{Si}$ doping of $\mathrm{CrCoNiFe}$ does not significantly affect its mechanical properties which suggests $\mathrm{Si}$ is a cheap and abundant dopant for $\mathrm{CrCoNiFe}$-based alloys.

\section{Conflicts of interest}

There are no conflicts to declare.

\section{Acknowledgments}

The authors acknowledge CSC - IT Center for Science, Finland for computational resources and the financial support provided by the Academy of Finland (grant No. 311934).

\section{References}

1. J.W. Yeh, S.K. Chen, S.J. Lin, J.Y. Gan, T.S. Chin, T.T. Shun, C.H. Tsau, S.Y. Chang, Nanostructured high-entropy alloys with multiple principal elements: Novel alloy design concepts and outcomes, Adv. Eng. Mater. 6 (2004) 299-303.

2. M. H. Tsai, Three strategies for the design of advanced high-entropy alloys, Entropy. 18 (2016) 252.

3. S. Singh, N. Wanderka, B.S. Murty, U. Glatzel, J. Banhart, Decomposition in multi-component AlCoCrCuFeNi high-entropy alloy, Acta Mater. 59 (2011) 182-190.

4. W.R. Wang, W.L.Wang, S.C. Wang, Y.C. Tsai, C.H. Lai, J.W. Yeh, Effects of Al addition on the microstructure and mechanical property of $\mathrm{Al}_{\mathrm{x}} \mathrm{CoCrFeNi}$ high-entropy alloys, Intermetallics. 26 (2012) 44-51. 
5. H. Chen, Q. Fang, K. Zhou, Y. Liu, J. Li, Unraveling atomic-scale crystallization and microstructural evolution of a selective laser melted FeCrNi medium-entropy alloy, CrystEngComm. 22 (2020) 4136-4146.

6. Y. Sun, Y. Xia, L. Kuai, H. Sun, W. Cao, M. Huttula, A. P. Honkanen, M. Viljanen, S. Huotari, B. Geng, Defect-driven enhancement of electrochemical oxygen evolution on $\mathrm{Fe}-\mathrm{Co}-\mathrm{Al}$ ternary hydroxides, ChemSusChem. 12 (2019) 2564-2569.

7. E. Airiskallio, E. Nurmia, M.H. Heinonen, I.J. Väyrynena, K. Kokko, M. Ropo, M.P.J. Punkkinen, H. Pitkänen, M. Alatalo, J. Kollárh, B. Johansson, L.Vitos, High temperature oxidation of Fe-Al and $\mathrm{Fe}-\mathrm{Cr}-\mathrm{Al}$ alloys: The role of $\mathrm{Cr}$ as a chemically active element, Corros. Sci. 52 (2010) 3394-3404.

8. E. Airiskallio, E. Nurmi, M.H. Heinonen, I.J. Väyrynen, K. Kokko, M. Ropo, M.P.J. Punkkinen, H. Pitkänen, M. Alatalo, J. Kollár, B. Johansson, L. Vitos, Phys. Rev. B. 81 (2010) 033105.

9. C. Han, Q. Fang, Y. Shi, S. B. Tor, C. K. Chua, K. Zhou, Recent advances on high-entropy alloys for 3D printing, Adv. Mater. 32 (2020) 1903855.

10. S.G. Ma, Y. Zhang, Effect of $\mathrm{Nb}$ addition on the microstructure and properties of AlCoCrFeNi highentropy alloy, Mater. Sci. Eng. A. 532 (2012) 480-486.

11. L. Liu, J.B. Zhu, L. Li, J.C. Li, Q. Jiang, Microstructure and tensile properties of FeMnNiCuCoSn $n_{x}$ high entropy alloys, Mater. Des. 44 (2013) 223-227.

12. K.B. Kim, P.J. Warren, B. Cantor, Metallic glass formation in multicomponent (Ti, Zr, Hf, Nb)-(Ni, Cu,Ag)-Al alloys, J. Non-Cryst. Solids. 317 (2003) 17-22.

13. D. Raabe, C.C. Tasan, H. Springer, M. Bausch, From high-entropy alloys to high-entropy steels, Steel Res. Int. 86 (2015) 1127-1138.

14. P. Yu, Y. Zhuang, J. P. Chou, J. Wei, Y. C. Lo, A. Hu, The influence of dilute aluminum and molybdenum on stacking fault and twin formation in FeNiCoCr-based high entropy alloys based on density functional theory, Sci. Rep. 9 (2019) 10940.

15. C. Ng, S. Guo, J. Luan, Q. Wang, J. Lu, S. Shi, C.T. Liu, Phase stability and tensile properties of Co-free $\mathrm{Al}_{0.5} \mathrm{CrCuFeNi}_{2}$ high-entropy alloys, J. Alloys Compd. 584 (2014) 530-537.

16. S. Guo, C. Ng, C.T. Liu, Anomalous solidification microstructures in Co-free $\mathrm{Al}_{\mathrm{x}} \mathrm{CrCuFeNi}_{2}$ highentropy alloys, J. Alloys Compd. 557 (2013) 77-81.

17. B. Cantor, I.T.H. Chang, P. Knight, A.J.B. Vincent, Microstructural development in equiatomic multicomponent alloys, Mater. Sci. Eng. A. 375 (2004) 213-218.

18. C. Li, M. Zhao, J. C. Li, Q. Jiang, B2 structure of high-entropy alloys with addition of Al, J. Alloys Compd. 104 (2008) 113504.

19. G. Wang, Y. Yang, R. He, C. Tan, M. Huttula, W. Cao, A novel high entropy CoFeCrNiCu alloy filler to braze SiC ceramics, J. Eur. Ceram. 40 (2020) 3391-3398.

20. K.K.Tseng, Y. C. Yang, C.C. Juan, T.S. Chin, C.W. Tsai, J.W. Yeh, A light-weight high-entropy alloy $\mathrm{Al}_{20} \mathrm{Be}_{20} \mathrm{Fe}_{10} \mathrm{Si}_{15} \mathrm{Ti}_{35}$, Sci. China Technol. Sci. 61 (2018) 184-188. 
21. T.T. Zuo, R.B. Li, X.J. Ren, Y. Zhang, Effects of Al and Si addition on the structure and properties of CoFeNi equal atomic ratio alloy, J. Magn. Magn. Mater. 371 (2014) 60-68.

22. J.P. Perdew, K. Burke, M. Ernzerhof, Generalized gradient approximation made simple, Phys. Rev. Lett. 77 (1996) 3865-3868.

23. G. Kresse, J. Furthmüller, Efficient iterative schemes for ab initio total-energy calculations using a plane-wave basis set, Phys. Rev. B, 54 (1996) 11169.

24. R. Gaillac, P. Pullumbi, F. X. Coudert, ELATE: an open-source online application for analysis and visualization of elastic tensors, J. Phys. Condens. Matter. 28 (2016) 275201.

25. H. Huang, X. Li, Z. Dong, W. Li, S. Huang, D. Meng, X. Lai, T Liu, S. Zhu, L. Vitos, Critical stress for twinning nucleation in CrCoNi-based medium and high entropy alloys. Acta Mater. 149 (2018) 388-396.

26. Z. Wu, H. Bei, G.M. Pharr, E.P. George, Temperature dependence of the mechanical properties of equiatomic solid solution alloys with face-centered cubic crystal structures, Acta Mater. 81 (2014) $428-441$.

27. Z. Wu, Y. Gao, H. Bei, Thermal activation mechanisms and labusch-type strengthening analysis for a family of high-entropy and equiatomic solidsolution alloys, Acta Mater. 120 (2016) 108-119.

28. K. Persson, Materials Data on CrFeCoNi (SG:6) by Materials Project. United States. (2016) https://www.osti.gov/servlets/purl/1328976. (accessed October 15, 2016).

29. F. Mouhat, F.X. Coudert, Necessary and sufficient elastic stability conditions in various crystal systems, Phys. Rev. B. 90 (2014) 224104.

30. W. Voigt, Lehrbuch der Kristallphysik, Vieweg + Teubner Verlag, Germany, 1928.

31. A. Reuss, Z. Angew, Berechnung del fliessgrenze von mischkristallen auf grund der plastizitatbedingung for einkristalle, Math. Mech. 9 (1929) 49-58.

32. R. Hill, The elastic behaviour of a crystalline aggregate, Proc. Phys. Soc. A. 65 (1953) 349-354.

33. S.F. Pugh, Relations between the elastic moduli and the plastic properties of polycrystalline pure metals, Philos. Mag. 45 (1954) 823-843.

34. I. N. Frantsevich, F. F. Voronov, S. A. Bokuta, Elastic constants and elastic moduli of metals and insulators handbook, Naukova Dumka, Kiev. (1983) 60-180.

35. D. Pettifor, Theoretical predictions of structure and related properties of intermetallics, Mater. Sci. Technol. 8 (1992) 345-349.

36. P. Ravindran, L. Fast, P.A. Korzhavyi, B. Johansson, J. Wills, O. Eriksson, Density functional theory for calculation of elastic properties of orthorhombic crystals: Application to TiSi 2 , J. Appl. Phys. 84 (1998) 4891-4904.

37. D.H. Chung, W.R. Buessem, The elastic anisotropy of crystals, J. Appl. Phys. 38 (1967) 2010-2012.

38. J.F. Nye, Physical properties of crystals, Oxford University Press: Oxford, UK, 1985. 
39. D. H. Wu, H. C. Wang, L. T. Wei, R. K. Pan, B. Y. Tang, First-principles study of structural stability and elastic properties of $\mathrm{MgPd}_{3}$ and its hydride. J. Magnes. Alloy. 2 (2014) 165-174.

40. M. G. Goesten, R. Hoffmann, Mirrors of bonding in metal halide perovskites. J. Am. Chem. Soc. 140 (2018) 12996-13010.

41. R. F. W. Bader, Atoms in Molecules - A Quantum Theory, Oxford University Press, New York, 1990.

42. K. V. Shanavas, M. A. McGuire, D. S. Parker, Electronic and magnetic properties of Si substituted $\mathrm{Fe}_{3} \mathrm{Ge}$. J. App. Phys. 118 (2015) 123902. 